\title{
Displasia Tanatóforica
}

Tanatoforic Dysplasia

\section{David Giovanny Morales Iriarte *}

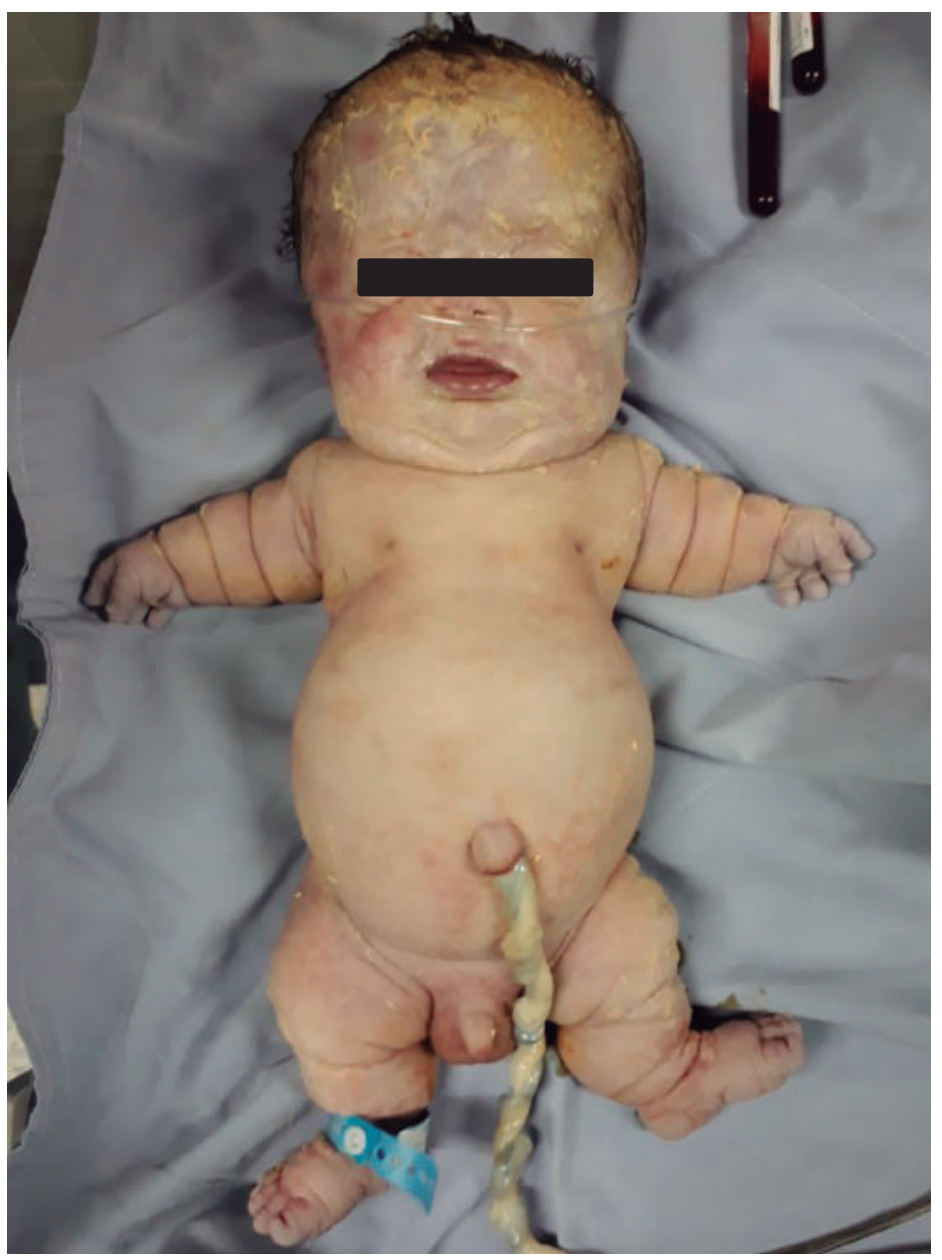

La displasia tanatofórica es una acondrodisplasia, pertenece a la categoría de defectos de huesos tubulares, generalmente de curso letal, se presenta con tronco de tamaño normal y platispondilia. ${ }^{(1)} \mathrm{Su}$ incidencia es 1/50 000 nacidos vivos.

Los rasgos morfológicos característicos de esta patología se aprecian en la época prenatal. Al final del primer trimestre, se aprecia el acortamiento de los huesos

*Médico residente de 3er año de Pediatria, Unah-VH Dirigir correspondecia a: dgio.morales@gmail.com

Recibido: 20 de Febrero 2019 Aprobado: 18 de Agosto 2019 largos por ecografía. En el segundo trimestre se observa una deficiencia en el crecimiento. Acompañado de macrocefalia, ventriculomegalia y un cráneo bien mineralizado. ${ }^{(1)}$

Los recién nacidos son macrocefálicos y tienen una fontanela anterior grande, frente prominente, hipoplasia de la región mediofacial grave y proptosis. Las extremidades son micromélicas, y las manos presentan braquidactilia con configuración de tridente. El tórax es angosto y tiene forma de campana. ${ }^{(2)}$ 


\section{REFERENCIAS BIBLIOGRÁFICAS}

1. Álvaro Lezid Padilla Rodríguez, ${ }^{*}$ Marco A Durán Padilla, ${ }^{* *}$ Belinda R Davies ${ }^{* *}$ Displasia tanatofórica: revisión de los criterios de diagnóstico en 5 casos de autopsia revista mexicana de pediatría Vol. 72, Núm. 3 - May.-Jun. 2005 pp 126-132.
2. Alejandro Giraldo-Cuartas, M.D Displasia tanatofórica. Reporte de un caso y revisión Rev Colomb Obstet Ginecol vol.59 no.4 Bogotá Oct./Dec. 2008. 